\title{
Experiment and finite element analysis of U-profile subjected to dynamic loading
}

\author{
Martin Rund ${ }^{1}$, Martin Mašek ${ }^{l}$, Jan Džugan ${ }^{l}$, Pavel Konopík ${ }^{l}$ and Jiři Janovec ${ }^{2}$ \\ ${ }^{1}$ COMTES FHT a.s., Průmyslová 995, Dobřany 33441, Czech Republic \\ ${ }^{2}$ CTU in Prague, Dept. Mat. Engineering, Karlovo n. 13, Prague 12135, Czech Republic
}

\begin{abstract}
The presented study deals with the FEM simulation of dynamic behaviour of U-profile crash under three point bent loading conditions verified by experimental investigations. The material ductile damage behaviour under wide strain rate region covering $0.001-1000 \mathrm{~s}^{-1}$ was experimentally determined with the use of standard and micro tensile tests (M-TT). DIC systems were used for strain field measurements under quasi-static and dynamic loading conditions. Based on these experimental data, material model considering ductile damage was established in Abaqus/Explicit code. Additionally, also metallographic investigations were performed for the fracture behaviour description.
\end{abstract}

\section{Introduction}

Over the last decade average weight of midsize car has reduced from $1400 \mathrm{~kg}$ to $1150 \mathrm{~kg}$ resulting in $18 \%$ reduction of total car weight. Similar trend is also witnessed across all segments of passenger car. This was possible due to implementation of High Strength Steel (HSS) and Advanced High Strength Steel (AHSS) in automotive body structures.

Automotive and Transport sectors are making increasing use of stainless steels to reduce weight, improve aesthetics, enhance safety and minimize life cycle cost. Characterized by superior fire and corrosion resistance, they ensure safety and reliability. Since stainless steels exhibit superior combination of high strength, ductility, formability and toughness compared to other metals and alloys, the intrinsic weight of vehicle decreases and its load carrying capacity and fuel efficiency increases. Maintenance cost is naturally lower and stainless steel component at the end of its long life is easily recycled. On account of transformation induced plasticity, these steels develop very high strength coupled with good formability in cold rolled tempers and constitute ideal material for structural components. The exceptional strength to weight ratio and energy absorption capacity enables the designers to reduce weight and enhance crash worthiness while ensuring longer life span due to superior corrosion resistance. As new austenitic, ferritic and duplex stainless steels are evolving, automotive and transport industry is intensively exploring their potential. On the other hand, it is important to mention, that austenitic stainless steels can be expensive choices for some components and joining of these steels can be challenge. Therefore, the Third Generation AHSS seeks to offer comparable or improved capabilities at significantly lower cost [1].
Hand in hand with above mentioned goes the trend of reduction of greenhouse gas emission. Automotive industry addresses the trend by reduction of fuel consumption by lowering the car body weight thanks to high strength steels application. There is a direct correlation between weight of vehicle and fuel consumption. A $10 \%$ of weight reduction can lead to $1.9-8.2 \%$ savings in fuel consumption [2]. According to the study performed be Forschungsgesellschaft Kraftfahrwesen mbH Aachen (FKA) [3], vehicle mass can be reduced by $25 \%$ through the application of modern AHSS steel and $50 \%$ by application of aluminium. Using e.g. AISI301 in the B-pillar leads to lightening by $1.8 \mathrm{~kg}$ (24\%) compared to DP600 which has been used until now [4].

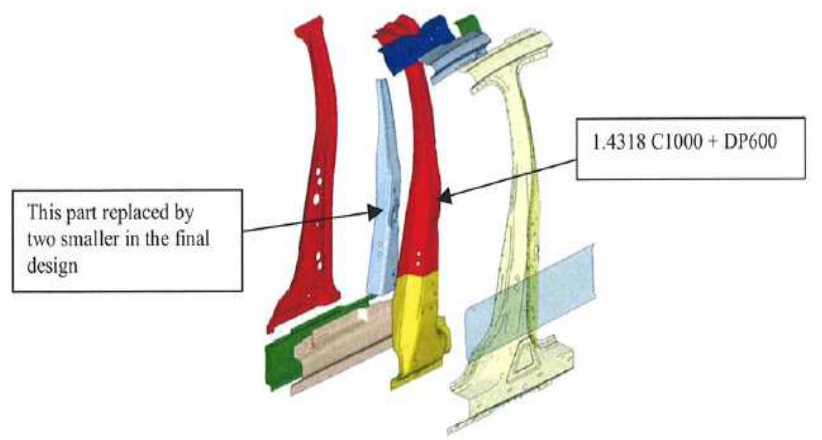

Fig. 1. Adapting of the B-pillar with strain less steel [4].

Additional reason for using stainless steel in the body structure of an automotive is its capability to absorb impact energy in a crash situation. This, in combination with the good formability and joining capability, makes these materials often as a first choice for the design of the body-in-white (BIW) structure. Compared to the other types of steel, the ductile austenitic steel behave a bit like "chewing - gum", and the excellent combination 
in between the mechanical ductility and the corrosion resistance has ensured that the austenitic steels are very attractive for automotive industry.

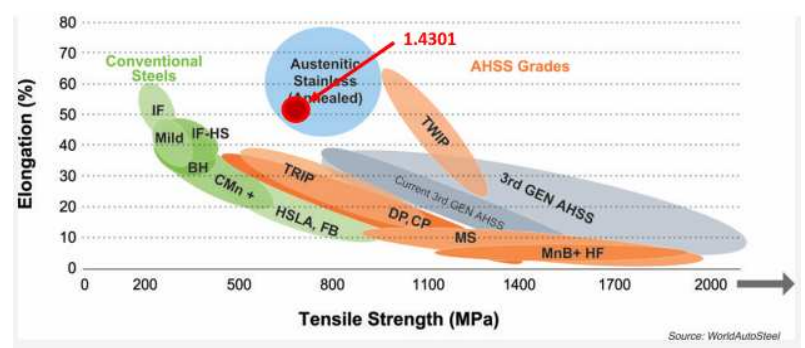

Fig. 2. Ductility diagram with marked position of investigated steel 1.4301 [1].

There are variety of phenomenological models which are validated with a specimen level to simulate plasticity and fracture using FEA. Development of such a model is still very active field of research in order to optimize the crash performance [5-9]. All of these constitutive models need sets of specimens for its calibration. This attitude leads to a very accurate setting of the coupled and uncoupled fracture models. But it is indisputable, this attitude is very time and money consuming process. Thus this approach is not very convenient for fast analysis and at the initial design stages. Lee et al. [10] suggested calibration method that bypasses a need for numerical modelling and simulations. This model is based on approximate closed form solutions for triaxiality in the critical locations as a function of the equivalent strain. Calibration of such a model can be done from flat (if satisfied plane stress condition) or round tensile test specimen. In both cases the critical damage parameters are determined from the exponent of power law. This simplified approach was applied here. The material ductile damage behaviour at strain rates $0.001-1000 \mathrm{~s}^{-1}$ was experimentally determined with the use of standard and micro tensile tests (M-TT). DIC systems were used for strain field measurements under quasi-static and dynamic loading conditions. Based on these experimental data, material model considering ductile damage was established in Abaqus/Explicit code.

Additionally, also metallographic investigations were performed for the fracture behaviour description. Validation of a material model on outwardly simple three-point bending tests of U-shape profile subjected to the dynamic loading was carried out.

\section{Experimental program}

\subsection{Material}

Experiments were conducted on a $2 \mathrm{~mm}$ thick cold rolled stainless steel AISI 304 (1.4301) provided in $1000 \mathrm{x}$ $1000 \mathrm{~mm}^{2}$ pieces. Chemical composition was measured by means of optical emission spectrometer Bruker Q4 TASMAN, results are summarized in Table 1.

\subsection{Mechanical tests}

Uniaxial tensile tests were carried out in the rolling direction. Tensile test were done at strain rates $0.001 ; 10$ and $1000 \mathrm{~s}^{-1}$. Depending on a target strain rate, three tensile test specimen geometries were used (displayed in Fig. 3). In all cases, three samples were tested at given level of strain rate.

Table 1. Chemical composition of experimental material 1.4301 .

\begin{tabular}{|c|c|c|c|c|c|c|c|c|c|}
\hline $\mathbf{C}$ & $\mathbf{S i}$ & $\mathbf{M n}$ & $\mathbf{P}$ & $\mathbf{S}$ & $\mathbf{C r}$ & $\mathbf{M o}$ & $\mathbf{N i}$ & $\mathbf{C u}$ & $\mathbf{A l}$ \\
\hline 0,025 & 0,21 & 1,79 & 0,04 & 0 & 18,7 & 0,13 & 8,07 & 0,28 & 0 \\
\hline $\mathbf{B}$ & $\mathbf{C o}$ & $\mathbf{N b}$ & $\mathbf{S n}$ & $\mathbf{T i}$ & $\mathbf{V}$ & $\mathbf{W}$ & \\
\hline$<0,001$ & 0,16 & 0,02 & 0,01 & 0 & 0,07 & $<0,020$ \\
\hline
\end{tabular}

Specimens geometry depicted in Fig. 3a were tested in servo-electric testing machine Zwick/Roell, deformation was measured by Laser speckle extensometer with gauge length $\mathrm{Lo}=50 \mathrm{~mm}$. Specimens displayed in Fig. $3 \mathrm{~b}$ were tested on servo hydraulic testing machine MTS Bionix. Deformation of the specimen was measured by means of mechanical extensometer with gauge length $\mathrm{Lo}=20 \mathrm{~mm}$. Above mentioned tests were done with constant crosshead velocity. The last specimen geometry (Fig. 3c) was subjected to the highest strain rate loading $\left(1000 \mathrm{~s}^{-1}\right)$ using Drop Weight Tower IM10 T. Such a testing suffer often on ringing in the force record, therefore, force was measured by means of strain gauges placed on specimen shoulders. The dynamic strain measurement was carried out with the use of High speed camera Phantom V710 and subsequently evaluated for gauge length $\mathrm{Lo}=5 \mathrm{~mm}$.
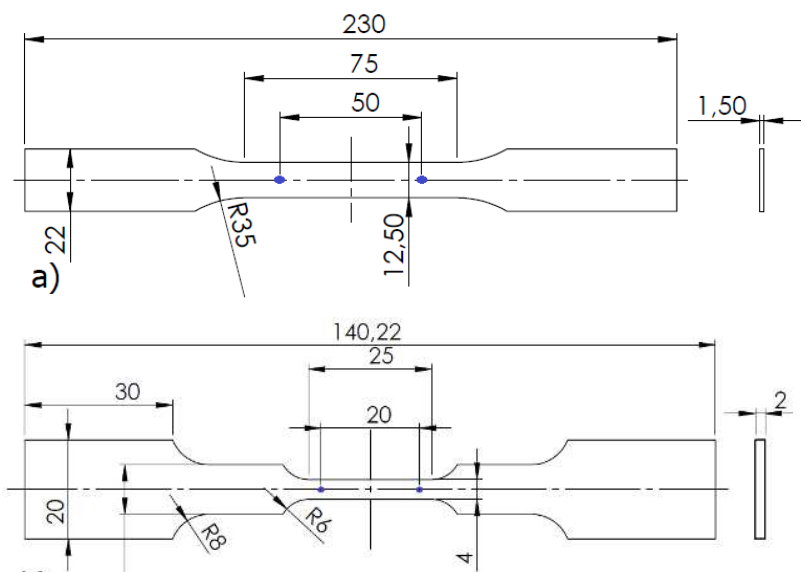

b) 으

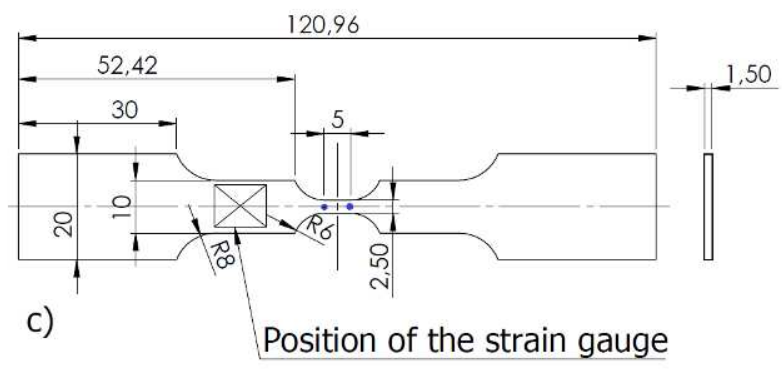

Fig. 3. Geometries of tensile tests specimen for different strain

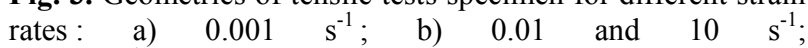
c) $1000 \mathrm{~s}^{-1}$. 


\subsection{Results of mechanical testing}

Tensile tests results are summarized in Table 2 . Graphical representations of the results are shown in Fig. 4. Strain rate sensitivity of the material 1.4301 is depicted in Fig. 5.

Table 2. Averaged results of tensile tests.

\begin{tabular}{ccccccc}
$\begin{array}{c}\text { Strain rate } \\
\mathrm{s}^{-1}\end{array}$ & $\begin{array}{c}\mathbf{R}_{\mathrm{p} 0,2} \\
\mathrm{MPa}\end{array}$ & $\begin{array}{c}\mathbf{R}_{\mathbf{m}} \\
\mathrm{MPa}\end{array}$ & $\begin{array}{c}\mathbf{A}_{\mathbf{g}} \\
\%\end{array}$ & $\begin{array}{c}\mathbf{A}_{\mathbf{5}} \\
\%\end{array}$ & $\begin{array}{c}\mathbf{Z} \\
\%\end{array}$ & Geometry \\
\hline 0,001 & 331,0 & 690,4 & 53,4 & 71,0 & 75,6 & Lo 50 \\
\hline 0,01 & 352,5 & 666,1 & 45,3 & 56,2 & 63,1 & Lo 20 \\
\hline 10 & 418,9 & 708,4 & 33,9 & 52,5 & 53,6 & Lo 20 \\
\hline 1000 & 470,6 & 855,7 & 38,2 & 73,6 & 44,8 & Lo 5 \\
\hline
\end{tabular}

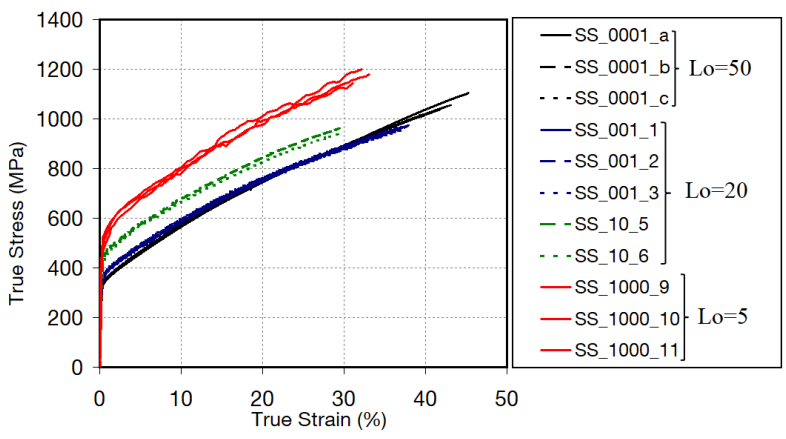

Fig. 4. Comparison of measured Stress-Strain curves for various strain rates.

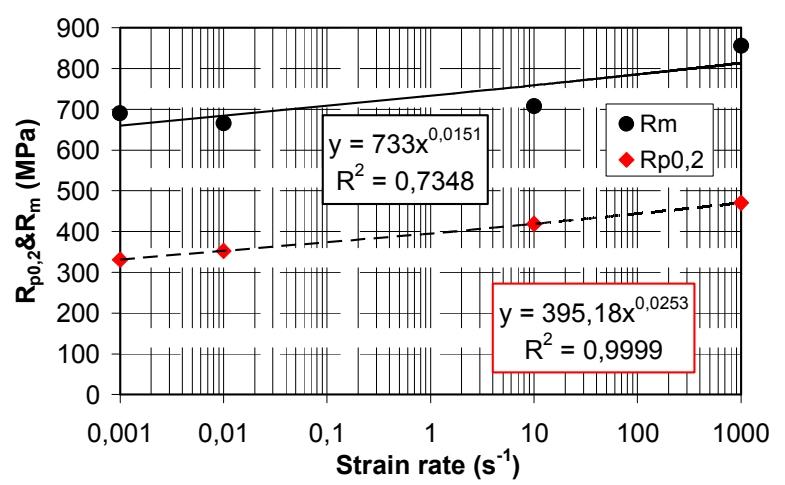

Fig. 5. Evaluation of Yield stress and Ultimate strength with respect to the strain rate.

\subsection{Finite element model}

Simulations of the test were conducted with the nonlinear finite element solver Abaqus version 2017 [11]. Johnson-Cook model of plasticity was used in order to define the strain-rate effect on the material model, eq. (1). Parameter $A$ represents the yield stress and parameters $B$ and $n$ are material constants describing true stress-true strain curve. The strain-rate dependency is defined by constant $C$ and the initial strain-rate $\dot{\varepsilon}_{0}$. These constants were defined based on the tensile tests results. Summarization of fitted Johnson-Cook parameters is shown in Table 3. The model of tensile specimen is displayed in Fig. 6. To reduce computation time the U-shape profile was simulated using 2D elements S4R and to keep consistence between simulations the tensile specimen was also simulated with
$2 \mathrm{D}$ elements. In both simulations, the tensile tests and the U-shape tests, the same element size was used, because the failure strains can be expressed as a function of the element size (Ehlers S. [12]). Results of Forcedisplacement curves are shown in Fig. 7 (the damage model described in following chapter is included in simulation) similarly it was done for other strain rates.

$$
\sigma_{y}=\left(A+B \bar{\varepsilon}^{p n}\right)\left(1+C \ln \left(\frac{\varepsilon}{\varepsilon_{0}^{*}}\right)\right)
$$

Table 3. Constants of the Jonson - Cook plasticity model.

\begin{tabular}{ccccc} 
A & B & n & C & $\dot{\boldsymbol{\varepsilon}}_{0}$ \\
$\mathrm{MPa}$ & $\mathrm{MPa}$ & - & - & s $^{-1}$ \\
\hline 200 & 1190 & 0,455 & 0,012 & 0,01 \\
\hline
\end{tabular}

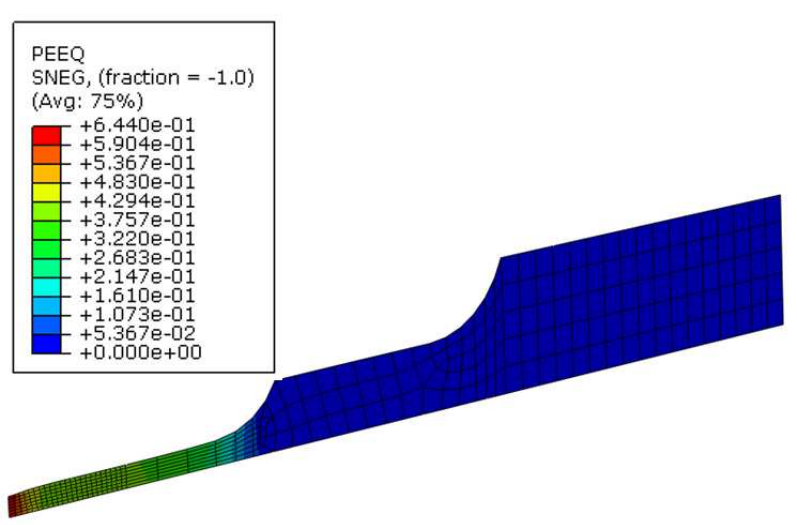

Fig. 6. Simulation of the tensile tests specimen with $\mathrm{L} 0=20 \mathrm{~mm}$.

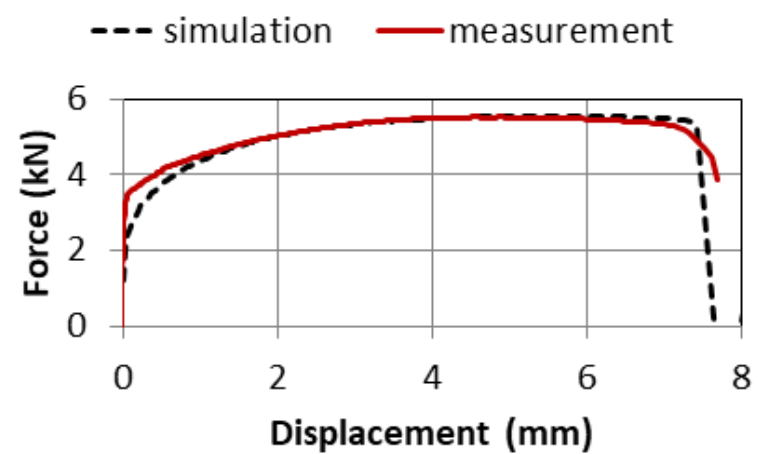

Fig. 7. Comparison of the simulation and measurement for strain rate $10 \mathrm{~s}^{-1}$ and specimen with $\mathrm{L}_{0}=50 \mathrm{~mm}$.

\subsection{Failure criteria}

Historically, most commercial finite element software support Von Mises constant plastic strain based failure criteria. The Johnson-Cook failure criterion as a function of stress triaxiality provides a variable failure strain curve, but failure at the low and negative stress triaxiality cannot be described properly. Bao-Wierzbicky [13] suggested a failure strain in three regions representing different modes of failure. Region I $(1 / 3<\eta)$ is related to high levels of stress triaxiality which promotes nucleation, growth, and coalescence of voids 
leading to ductile fracture. Region III $(-1 / 3<\eta \leq 0)$ is negative values of stress triaxiality which represent shear fracture due to shear band localization. Region II $(0<\eta<1 / 3)$ comprises positive but low levels of stress triaxiality representing mixed mode fracture. In theory, the failure initiation envelope for a given material is developed through a series of physical tests with many different specimen geometries to characterize different levels of near-constant stress triaxiality in the vicinity of failure. In this study, the failure initiation is constructed based on calibration method using measurements from standard uniaxial tensile tests. According to Lee and Wierzbicki [10], this calibration method estimates a failure initiation envelope that is within 10 percent agreement of that based on the complete tests series.

The Bao-Wierzbicki failure initiation envelope is given by the following functions:

$$
\begin{array}{ccc}
\text { Region I } & \text { Region II } & \text { Region III } \\
\bar{\varepsilon}_{f}^{p^{l}}=a \frac{\eta_{0}}{\eta} & \bar{s}_{f}^{p l}=b+(a-b)\left(\frac{\eta}{\eta_{0}}\right)^{2} & \bar{\varepsilon}_{f}^{p^{l}}=\frac{a}{1+3 \eta}
\end{array}
$$

where constant $a$ represents critical fracture strain in pure shear $(\eta=0)$ and constant $b$ represents critical fracture strain in uniaxial tension $(\eta=1 / 3)$. Failure envelope related to the triaxiality with position of constant $a$ and $b$ is presented in Fig. 8. As the uniaxial tensile test has been performed, the critical fracture strain can be obtained with use of formula $b=\ln \left(A_{0} / A_{f}\right)$, where $A_{0}$ is an initial area of cross section and $A_{f}$ is area at the fracture. It is assumed that the material strain hardens isotopically according to the power law. From this assumption the effective strain to fracture is

$$
\bar{s}_{f}=\left(\frac{\bar{\sigma}_{f}}{K}\right)^{\frac{1}{n}}
$$

and the critical fracture strain in pure shear $(\eta=0)$ can be expressed by

$$
a=b\left(\frac{\sqrt{3}}{2}\right)^{\frac{1}{n}}
$$

\subsection{Verification of material model}

U-shaped profile was used for verification of material model. The geometry of the profile is depicted in Fig. 9. The groove $\mathrm{R}=5 \mathrm{~mm}$ was manufactured in the web sites of the profile in order to eliminate the influence of $U$ shaping of the profile on the fracture initiation,. Three point bend tests were conducted using DWT IM 10T (Fig.10). The aim was to reach crack in the notch area without additional deformation. Total weight of the striker was $31,025 \mathrm{~kg}$, span between the supports was $600 \mathrm{~mm}$. In total five tests were done with initial striker velocity $2 ; 3 ; 3.5 ; 3.75$ and $4.3 \mathrm{~m} / \mathrm{s}$ leading to different final specimens' deflections. U-shape profiles after the tests are presented in Fig. 11.

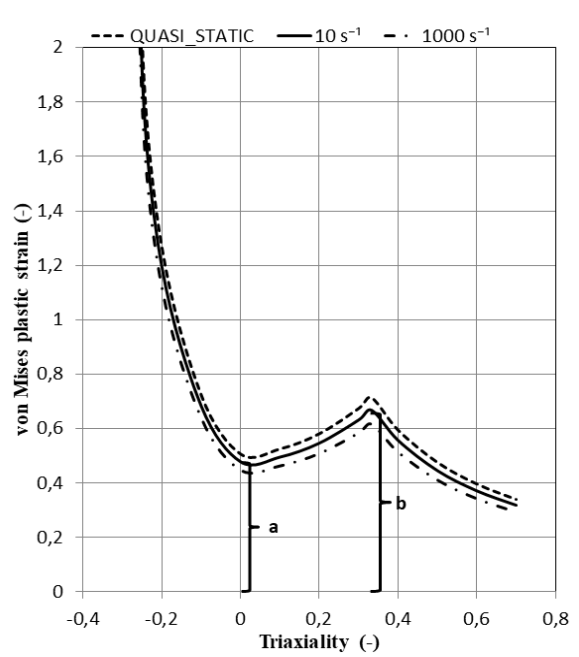

Fig. 8. Diagram showing the failure anvelope for the BW criterion to the stress triaxiality.

All tests were recorded by High speed camera Phantom $710 \mathrm{~V}$ at 17000 fps. A stochastic pattern was applied on specimens in order to allow subsequent Digital Image Correlation (DIC) analysis by system ARAMIS 4 M. A square facets $10 x 10$ pixels $(0.97 \times 0.97$ $\mathrm{mm}^{2}$ ) with 7 pixel overlapping were used for strain evaluation in the DIC system.

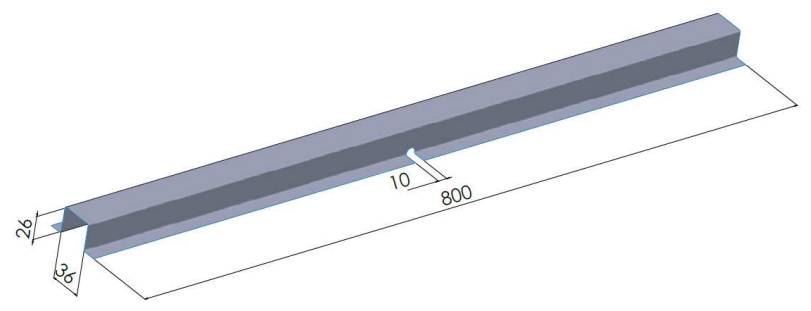

Fig. 9. Geometry of the U-shape specimen.

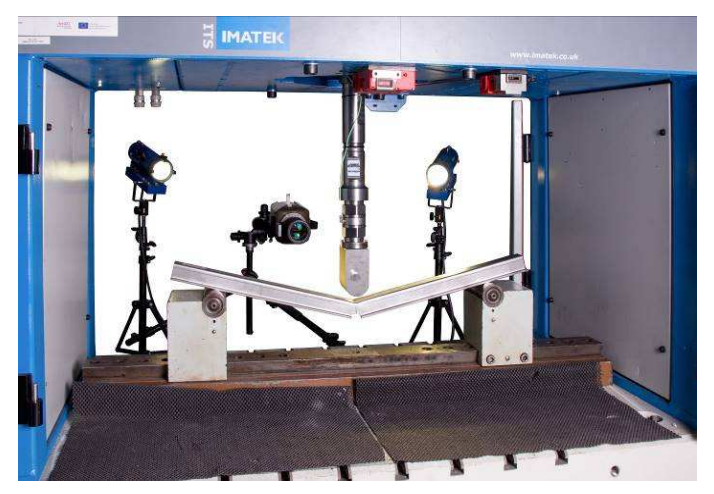

Fig. 10. Setup of the 3PB test of U-profile in DWT 10T.

\subsection{FEA analysis results}

During simulating of the U-shaped 3PB tests (Fig. 12), considerable influence of mesh size was found. Best fit between simulation and the real measurement was achieved by refinement of the mesh in the notch region. Final element size in the area of fracture was approximately $0.27 \mathrm{~mm}$. Time of crack initiation in simulation is comparable to the measurements. One small difference was found in the crack length growth. 
Crack in simulation starts a little bit earlier and its length exceeds the real crack length of about $2 \mathrm{~mm}$. This phenomenon can be attributed to reduced accuracy of this model. But all other parameters are in excellent agreement with measurements, as witnessed in graphs Fig. 13 - 14.

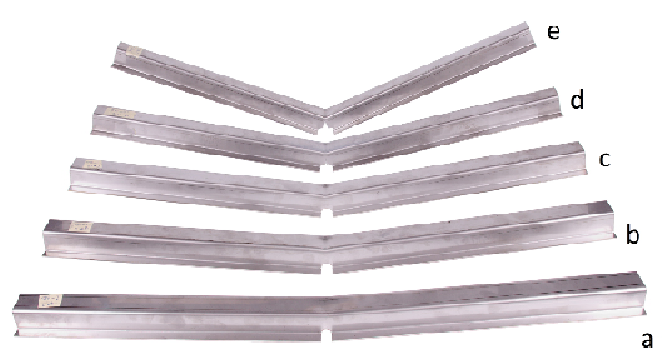

Fig. 11. U-profiles after the tests with different initial striker velocity, $a=2 \mathrm{~m} / \mathrm{s} ; \mathrm{b}=3 \mathrm{~m} / \mathrm{s} ; \mathrm{c}=3.5 \mathrm{~m} / \mathrm{s} ; \mathrm{d}=3.75 \mathrm{~m} / \mathrm{s} \mathrm{e}=4.3 \mathrm{~m} / \mathrm{s}$.

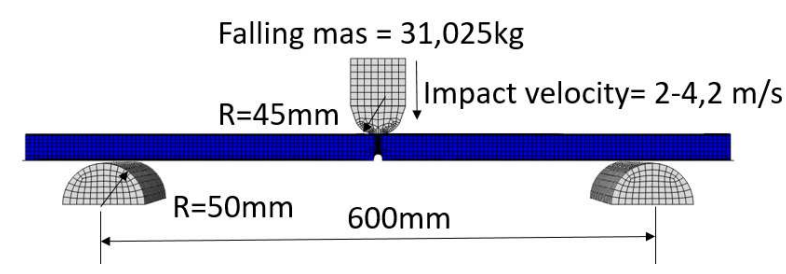

Fig. 12. Longitudinal view of the U-shaped test.

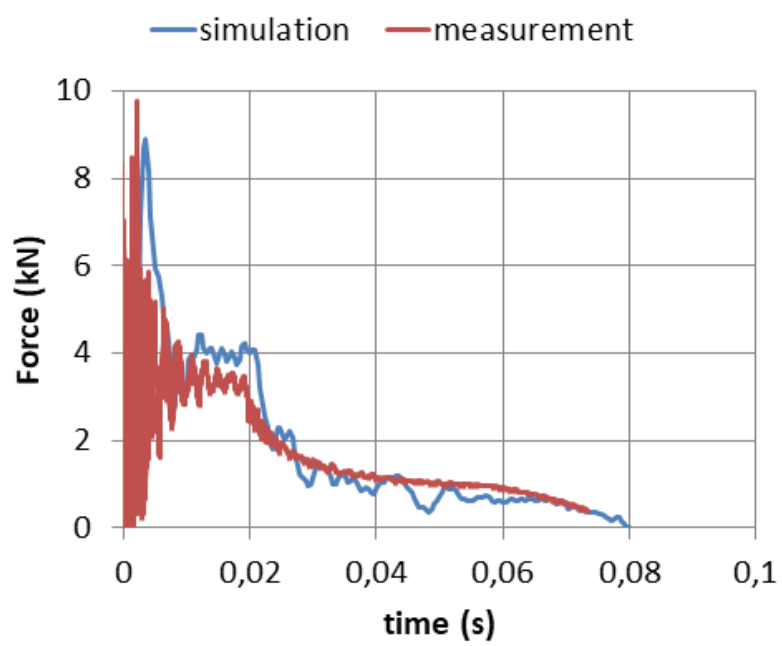

Fig. 13. Comparison of measured and simulated Force response.

Major and minor strains distribution evaluated by DIC in the region close to the notch was compared consequently with the simulation. The reference points were located at a distance of $0.25 \mathrm{~mm}$ from the notch in the direction of the crack growth for both the measurements and the simulation (Fig. 15). Resulting graph depicted in Fig. 16 declares conformity of the material model with tests.

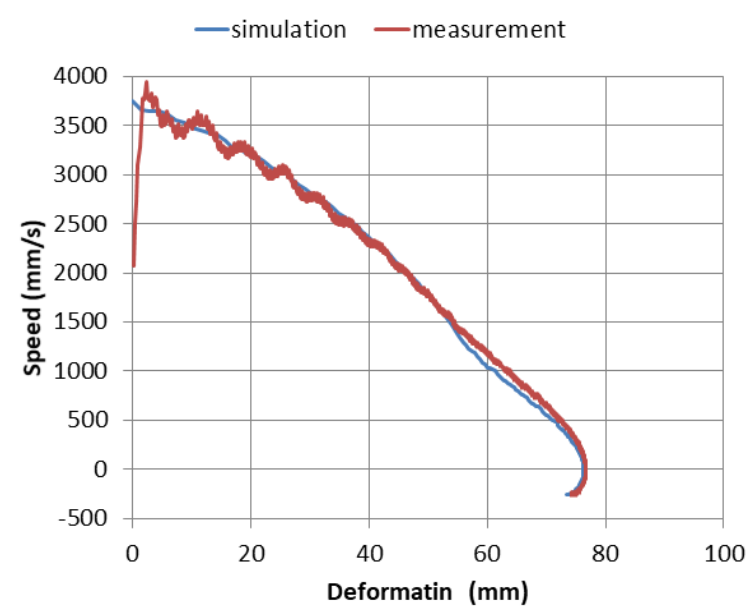

Fig. 14. Comparison of speed decrees with displacement.

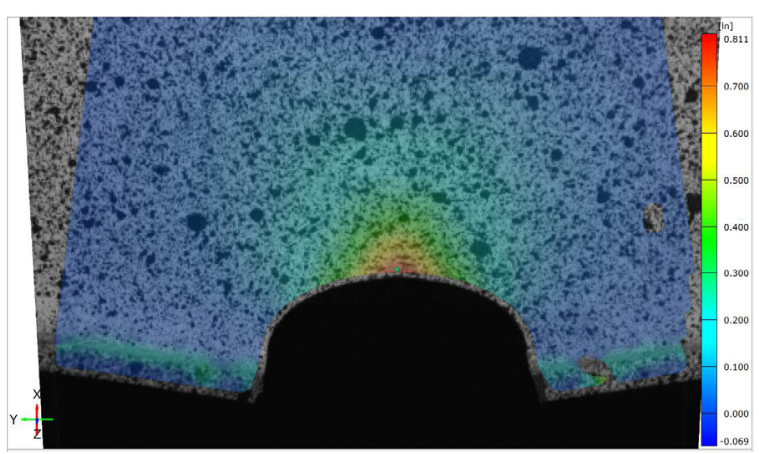

Fig. 15. Last stage before fracture, the major strain at fracture is $0.78(-)$.

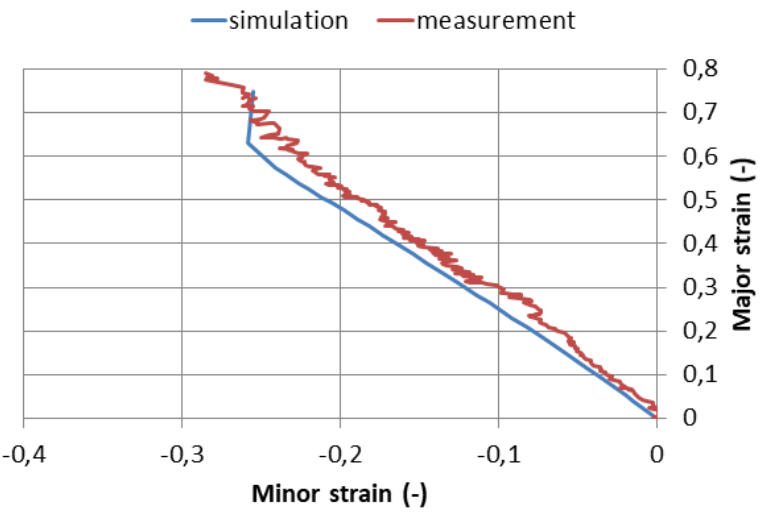

Fig. 16. Evolution of Minor-Major strain in the region of the notch compared for the tests and simulation.

\subsection{Fractography analysis}

Fractographic analysis of fracture surfaces was performed using a JEOL JSM 6380 Scanning Electron Microscope (SEM). From a macroscopic point of view, it is in all cases a tough quarry. All fractures were created by a micro-mechanism of ductile transgranual damage, as evidenced by the fracture morphology, which is formed by facet morphology. Fig. 17 - Fig. 19 illustate above mentioned finding. No strain rate dependent 
structural features were observed. This is in accordance with the stress state in individual specimens.

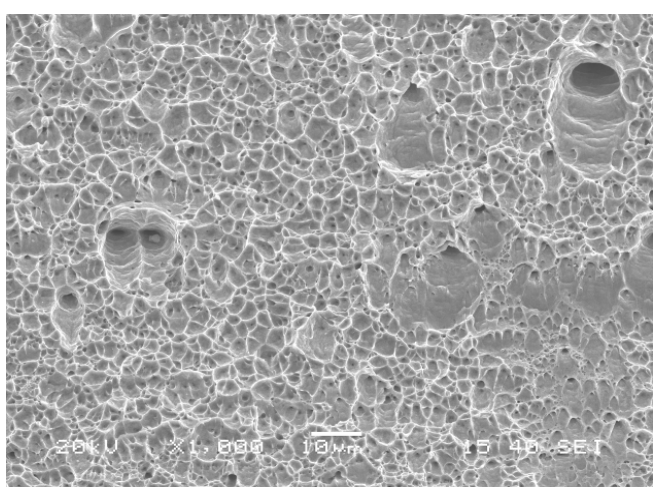

Fig. 17. Fracture surface of tensile specimen, $\mathrm{L}_{0}=50 \mathrm{~mm}$, strain rate $0.001 \mathrm{~s}^{-1}$.

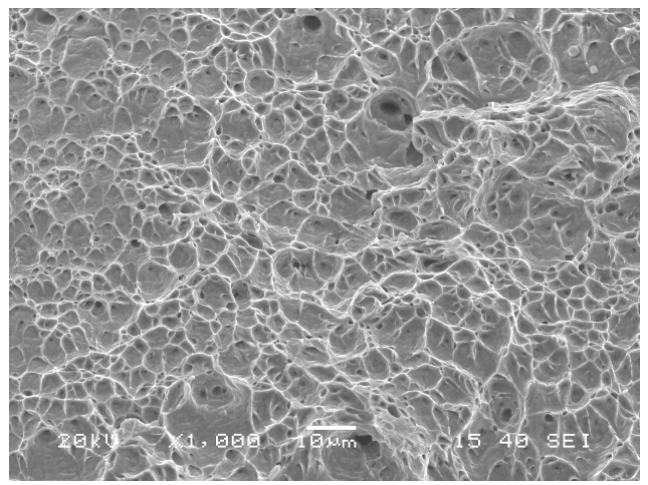

Fig. 18. Fracture surface of tensile specimen, $\mathrm{L}_{0}=5 \mathrm{~mm}$, strain rate $1000 \mathrm{~s}^{-1}$.

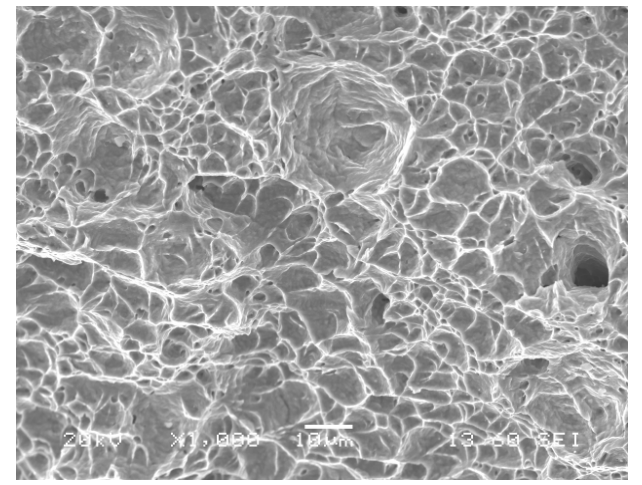

Fig. 19. Fracture surface of the U-profile, impact velocity 3.75 $\mathrm{m} / \mathrm{s}$.

\section{Conclusion}

It was proved that procedure for quick calibration for industrial applications presented by Lee [10] in comparison to the conventional calibration procedure is very quick tool, which significantly simplifies and facilitate the existing calibration procedure. The future work will compare the agreement between this approach and conventional one using MMC or Hosford Coulomb [14] fracture surface model including the influence of Lode parameter with more deep metallographic analysis.
This study was created by project Development of WestBohemian Centre of Materials and Metallurgy No.: LO1412, financed by the MEYS of the Czech Republic.

\section{References}

1. Anonymous "Automotive Steel Definitions," Available: $\quad$ http://www.worldautosteel.org/steelbasics/automotive-steel-definitions/.

2. Anonymous "Weight reduction and fuel economy" available : $\underline{\mathrm{http}: / / \mathrm{www} . w o r l d a u t o s t e e l . o r g / \text { steelyourw }}$ orld/mass-reduction/

3. Anonymous "Mass Reduction: a Report by FKA" availbele : $\mathrm{http}: / /$ www.worldautosteel.org/projects/ma ss-reduction/mass-reduction-a-report-by-fka/

4. Anonymous "Stainless Steel New Applications in Automotive Applications" http://www.worldstainless .org/transport_applications/automotive_applications -

5. Mohr, D., Marcadet, S.J., Micromechanicallymotivated phenomenological Hosford-Coulomb model for predicting ductile fracture initiation at low stress triaxialites. Int. J. Solids Struct. 67-68, 40-55 (2015)

6. Eller, T. , Greve, L. , Andres, M. , Medricky, M. , Hatscher, A. , Meinders, V., Van den Boogaard, A., Plasticity and fracture modeling of quenchhardenable boron steel with tailored properties. J. Mater. Process. Technol. 214, 1211-1227 (2014)

7. Bardelcik, A., Worswick, M., Winkler, S., Wells, M., A strain rate sensitive con- stitutive model for quenched boron steel with tailored properties. Int. J. Impact Eng. 50, 49-62 (2012)

8. Dzugan, J., et al., Identification of ductile damage parameters for pressure vessel steel. Nucl. Eng. Des. (2015),http://dx.doi.org/10.1016/j.nucengdes.2015.12 .014

9. Petr Kubík, P., Šebek, F., Petruška, J., Hůlka, J., Růžička, J., Španiel, M., Džugan, J., Prantl, A.: Calibration of Selected Ductile Fracture Criteria Using Two Types of Specimens, Key Engineering Materials, ISSN: 1662-9795, 592-593, pp.258-261 (2013)

10. Lee, Y.W., Wierzbicki, T.,"Quick Fracture Calibration for Industrial Use," Massachusetts Institute of Technology, Impact \& Crashworthiness Laboratory Report No. 115, Numerical failure analysis of three-point bending on martensitic hat assembly using advanced plasticity and fracture models for complex loading (2004)

11. Abaqus FEA. SIMULIA web site. Dassault Systèmes

12. Ehlers S. Strain and stress relation until fracture for finite element simulations of thincircular plate. ThinWalled Structures, 48(1):1-8 (2010)

13. Bao Y, Wierzbicki T., Evaluation and calibation of seven fracture models. J Mech Phys Solids, submitted for publication (2004)

14. Stephane J Marcadet, Christian C Roth, Borja Erice and Dirk Mohr, "A rate-dependent hosford-coulomb model for predicting ductile fracture at high strain rates," in Jan 1, pp. 1080 (2015) 